\title{
Isolation and Identification of a Phyllospheric Yeast Strain Capable of Utilizing BDE-3 as Sole Carbon and Energy Source
}

\author{
Xinwei Zhao ${ }^{1,2,3}$, Yaxiao Wang ${ }^{1,2}$, Yuling Li ${ }^{1,2}$, Kejiu Du ${ }^{1,2}$ \\ ${ }^{1}$ College of Forestry, Hebei Agricultural University, Baoding 071000, China \\ ${ }^{2}$ Hebei Provincial Key Laboratory of Tree Species Germplasm Resources and Forest Protection, Baoding 071000, China \\ ${ }^{3}$ State Key Laboratory of Tree Genetics and Breeding, Chinese Academy of Forestry, Beijing
}

Received: 9 July 2020

Accepted: 18 August 2020

\begin{abstract}
As a class of synthetic organic compounds widely used in varieties of industrial products, polybrominated diphenyl ethers (PBDEs) have attracted increasing attention for the properties of toxicity, bioaccumulation and persistence. In this paper, the phyllospheric yeast strain capable of aerobic degradation of 4-brominated diphenyl ether (BDE-3) was originally isolated from Populus tomentosa. Based on the morphological properties and the ITS sequence analysis, the obtained yeast was identified as Wickerhamomyces anomalus and designated Y1. The endurance ability of Y1 to BDE3 exposure was determined by BDE-3 concentration gradient experiment. BDE-3 removal efficiency analysis was conducted by applying GC- $\mu \mathrm{ECD}$ with initial BDE-3 content of $40 \mathrm{mg} / \mathrm{L}$. Results showed Y1 could remove $83.58 \pm 2.60 \%$ of $40 \mathrm{mg} / \mathrm{L}$ BDE-3 in 3-day aerobic incubation. The tolerance range of $\mathrm{pH}$ and $\mathrm{NaCl}$ concentration were determined for further engineering application. It could be the first report about PBDEs degradation by yeast strain, isolated from the phyllosphere of $P$. tomentos $a$ at the non-contaminated site of a subastral ecological niche, and might be advantageous in comprehensive exploitation of phytoremediation.
\end{abstract}

Keywords: Wickerhamomyces anomalus, BDE-3, phyllosphere, aerobic degradation

\section{Introduction}

Applied as one of the most effective and economical brominated flame retardants (BFRs), PBDEs have been widely used for more than three decades in varieties of manufactured materials [1]. Thanks to the extraordinary fire retarding capability, a great deal of wealth and

*e-mail: dukejiu@126.com life has been saved. Since BFRs were first detected in environmental samples in Sweden, interests as well as concerns in environmental distribution, behavior and fate of BFRs including PBDEs have grown sharply [2]. Mainly for massive industrial use and no chemical bound between PBDEs and body material, PBDEs are ubiquitously detected in various environmental media and biological samples even human beings [3]. In addition to the wide distribution, the properties of persistence, bioaccumulation and long distance transportation attracted world-wide concerns. Recently, 
PBDEs have been considered genotoxic, mutagenic and carcinogenic especially for low-brominated diphenyl ethers which are generated from high-brominated diphenyl ethers by debromination [4]. All of these posed detrimental threats to wildlife and human health. Therefore, it's necessary to establish effective technological approaches to deal with or reduce the pollution of PBDEs. In this research, BDE-3 was selected as a model congener of PBDEs to study its aerobic biodegradation.

Biodegradation is one of the most important natural attenuation processes for xenobiotic and synthetic chemicals in environment and deemed as a safe and effective way to remove them from the environment. Many efforts have been taken to degrade PBDEs by applying biotechnological approaches. Among them, a number of microorganisms responsible for debromination reactions have been enriched, isolated and identified from sludge and sediment [5-10]. Deng et al. (2011) investigated Lysinibacillus fusiformis DB-1, an aerobic bacteria isolated from sediments, to degrade decabromodiphenyl ether (BDE-209) [6]. Shi et al. (2013) demonstrated the possible aerobic transformation mechanism of PBDE-209 by analyzing of metabolites of BDE-209 metabolized by a Pseudomonas aeruginosa bacterium which was isolated from an e-waste dismantling area [7]. Moreover, one microalgae isolate Chlorella $\mathrm{SICh}$, isolated from wastewater, could reach $82-90 \%$ removal rate of a mixture of BDE-71 and BDE-209 (5:1) at $0.6 \mathrm{mg} / \mathrm{L}$ in seven days [11]. In addition to unicellular organisms, plants have been applied to remove PBDEs in vitro and in vivo [12-14]. Sun et al. (2013) used pumpkin to hydroponically expose to 2,2',4,4'-tetrabromodiphenyl ether (BDE-47) and found the formation of 5 kinds of debromination products and one methoxylated debromination product [13]. Also, Wang et al. (2012) observed the debrominated, hydroxylated and methoxylated products in maize hydroponically exposed to BDE-15, -28 and -47 [12]. Compared with bacteria and plants, little is known about the degradation of PBDEs by yeast strains though the unicellular eukaryotes play important roles in soil ecosystems as well as contaminated sludge and wastewater.

Widely distributed in the environment, various yeast strains have been reported for characterizing the removal capability to some hazardous chemicals. Magnusiomyces ingens LH-F1, obtained from the sea mud of a harbor adjacent to an azo dyes factory, was found capable of decolorizing various azo dyes [15]. Pichia anomala, isolated from crude oil contaminated soil, could degrade four kinds of polycyclic aromatic hydrocarbons (PAHs) alone or in combination [16]. Moreover, diverse yeast strains have been found participating in industrial wastewater purification with concomitant xenobiotic like color substances [17-19], phenol- and chlorophenol-related substances [19-20]. Because of the structure similarity of aromatic chemicals to PBDEs, the potential utilization of yeast strains for PBDEs removal seems attractive.

In this study, the yeast strain capable of aerobic degradation of 4-brominated diphenyl ether (BDE-3) was isolated form the phyllosphere of P. tomentosa, and identified base on morphological properties and the ITS sequence analysis. The $\mathrm{pH}$ and $\mathrm{NaCl}$ tolerance capability, growth curves with BDE-3 concentration gradient and BDE-3 removal and assimilation efficiency were investigated.

\section{Material and Methods}

\section{Reagents}

BDE-3 (purity $>98 \%$ ) used in this study was purchased from Tokyo Kasei Kogyo Co., Ltd. (TCL) and diluted with alcohol to $80 \mathrm{~g} \mathrm{~L}^{-1}$ before use. Biochemical reagents and solutions were of analytical grade or higher.

Synthetic Bushnell Hass Mineral Salts (BHMS) medium contains $(\mathrm{g} / \mathrm{L}): \mathrm{KH}_{2} \mathrm{PO}_{4}, 1 ; \mathrm{K}_{2} \mathrm{HPO}_{4}, 0.2$; $\mathrm{MgSO}_{4}-7 \mathrm{H}_{2} \mathrm{O}, 0.2 ; \mathrm{CaCl}_{2}, 0.02 ; \mathrm{NH}_{4} \mathrm{NO}_{3}, 1 ; \mathrm{NaCl}$, 2 ; and 2 droplets of $60 \% \mathrm{FeCl}_{3}$. BHMS medium supplemented with desired concentration of BDE-3 was used as BDE-3 degradation medium.

Potato Dextrose Agar (PDA) medium contains (g/L): Potato extract 3, glucose 20, agar 15. PDA medium was for culturing and screening of phenotypically different yeast strains.

Liquid PDA medium containing $(\mathrm{g} / \mathrm{L})$ : potato extract 3 and glucose 20 was used for activating microorganisms before the growth curve establishment and BDE-3 removal determination analysis. All the culture media were adjusted to $\mathrm{pH} 6.5$ and autoclaved at $115^{\circ} \mathrm{C}$ for $15 \mathrm{~min}$.

\section{Culturable Yeast Strains Isolation}

The P. tomentosa forest, aged 16, grows on West Campus of Agricultural University of Hebei, Baoding, China. The leaf material preparation and strains isolation were conducted following the method described by Zhao et al. [21]. The phyllospheric microbiota was subcultured for several times to obtain phenotypically different yeast colonies as many as possible.

\section{Screening BDE-3 Utilization Yeast Strains}

Prior to the screening, obtained culturable yeast strains need to be activated by incubating in liquid PDA medium. The initial yeast culture turbidity in liquid PDA was modulated to the optical density at $660 \mathrm{~nm}\left(\mathrm{OD}_{660}\right)$ of 0.100 , and the suspension culutre was incubated on a rotary shaker at $30^{\circ} \mathrm{C}$ and $150 \mathrm{rpm}$ for $24 \mathrm{~h}$. Cells were harvested by centrifugation (3000 rpm, $10 \mathrm{~min}, 4^{\circ} \mathrm{C}$ ), and then washed with BHMS medium (3000 rpm, $10 \mathrm{~min}, 4^{\circ} \mathrm{C}$ ) three times. The pellet of 
each strain was resuspend in BHMS medium and used for further investigations including the growth curve establishment and removal efficiency determination. $50 \mathrm{~mL}$ activated suspension containing $20 \mathrm{mg} \mathrm{L}^{-1}$ BDE-3 was incubated on a rotary shaker at $30^{\circ} \mathrm{C}$ and $200 \mathrm{rpm}$. The $\mathrm{OD}_{660}$ was measured every $12 \mathrm{~h}$ for the establishment of their growth curves using UV-visible spectrophotometer. The strains capable of growing on BDE-3 as sole source of carbon and energy were selected via screening 5 days later.

\section{Strain Identification}

The morphological properties were investigated to taxonomically characterize the BDE-3 degrading yeast strains. For the molecular identification, Internal Transcribed Spacer (ITS) sequences of obtained yeast were amplified by colony PCR. PCR amplification was performed using the general ITS primers 1 and 4 [22]. The sequence (5'-3') of primer 1 and 4 were TCCGTAGGTGAACCTGCGG and TCCTCCGCTTATTGATATGC, respectively. The amplification reaction was performed in a $50 \mu 1$ reaction system containing $1 \times \mathrm{PCR}$ buffer, $0.2 \mathrm{mM}$ dNTPs, $1 \mu \mathrm{M}$ each of forward and reverse primer, $0.4 \mathrm{mM}$ $\mathrm{MgCl}_{2}$ and $2 \mathrm{U}$ Tag DNA polymerase. The temperature profile was set as follows: on cycle of $5 \mathrm{~min}$ at $95^{\circ} \mathrm{C}$, followed by 35 cycles of $45 \mathrm{sec}$ at $95^{\circ} \mathrm{C}, 45 \mathrm{sec}$ at $52^{\circ} \mathrm{C}$, and $60 \mathrm{sec}$ at $72^{\circ} \mathrm{C}$, and one cycle of $10 \mathrm{~min}$ at $72^{\circ} \mathrm{C}$. The amplification products were subjected to electrophoresis in $1 \%$ agarose gel. Sequencing was performed after ITS DNA fragments extraction. The obtained ITS sequences were compared and aligned with sequences deposited in GenBank database using the BLAST program to compare similarity to other yeast ITS sequences. The ITS sequence of degrading yeasts and related sequences obtained from GenBank database were aligned by Clustal X (1.8). The aligned data was used to construct a phylogenetic tree using Neighbor-joining method by MEGA (Version 5.1) with 1000 bootstrap replicates.

\section{Growth Curve Establishment}

Growth curve of activated BDE-3 degrading yeast strain was conducted in $150 \mathrm{ml}$ Erlenmeyer flask containing $30 \mathrm{ml}$ BHMS medium supplied with different concentrations of BDE-3 (0, 100, 200, 300, 400, $500 \mathrm{mg} \mathrm{L}^{-1}$ ). The treatment group without adding BDE-3 was set as blank control. Treatments of BHMS medium supplied with different concentrations of BDE-3 and the one of the same volume of liquid PDA medium were set to to analyze the effects of nutritional condition on the yeast growth. The growth curves of all treatment groups were established by $\mathrm{OD}_{660}$ measurement. The incubation condition was on a rotary shaker at $30^{\circ} \mathrm{C}$ and $200 \mathrm{rpm}$. After every $\mathrm{OD}_{660}$ measurement, the batch of used suspensions were removed. Every treatment was set triplicate.

\section{Environmental Factors Tolerance Range Determination}

Activated BDE-3 degrading yeast strains cultured in BHMS with initial suspension $\mathrm{OD}_{660}$ of 0.100 and augmented with $300 \mathrm{mg} \mathrm{L}^{-1}$ BDE-3 were conducted to determine the tolerance range of $\mathrm{pH}$ and $\mathrm{NaCl}$. The range of $\mathrm{pH}$ was set as 4.0, 5.0, 6.0, 7.0, 8.0, 9.0, 10.0 and the $\mathrm{NaCl}$ concentration (mass concentration) was set as $0,0.5,1,2,3,4,5 \%$. Every treatment was set triplicate. The incubation condition was same to the section 2.5. The $\mathrm{OD}_{660}$ of suspension was measured after 5 days incubation.

\section{BDE-3 Removal Efficiency Determination}

Activated $30 \mathrm{~mL}$ yeast strain BHMS suspension in $150 \mathrm{~mL}$ Erlenmeyer flask supplied with $40 \mathrm{mg} \mathrm{L}^{-1}$ BDE-3 was set as removal treatment group. The thermal inactivation treatment group of $30 \mathrm{~mL}$ yeast strain BHMS suspension added $40 \mathrm{mg} \mathrm{L}^{-1} \mathrm{BDE}-3$ was set to determine the assimilation and adsorption effects of inactive yeast cells. The BHMS medium supplied with $40 \mathrm{mg} \mathrm{L}^{-1}$ BDE-3 was set as negative control to investigate the potential volatilization or non-biological degradation capacity. Every treatment was biological triplicate. The incubation condition was same to the section 2.5. After $72 \mathrm{~h}$ incubation, $10 \mathrm{~mL}$-hexane was added to incubation suspension. Incubation suspensions were treated on a rotary shaker at $20^{\circ} \mathrm{C}$ and $150 \mathrm{rpm}$ for $1 \mathrm{~h}$. Then, $1 \mathrm{~mL}$ supernate was extracted from the suspensions for removal efficiency analysis by applying gas chromatograph (Agilent Technologies 6890N) coupled with a micro-electron capture detector (Agilent Technologies, USA; GC- $\mu$ ECD). The capillary column, thermal settings and other procedure details were performed following the method described by Zhao et al. [21].

\section{Statistical Analysis}

Origin 8.5 was performed to form figures as well as calculate the mean value and standard deviation (SD) for replicates.

\section{Results and Discussion}

\section{Culturable Strains Isolation, Screening and Identification}

After several times of leaves sampling and strains isolation, a variety of culturable microorganisms on PDA medium were obtained. Through screening, one yeast strain with capability of aerobically metabolizing BDE-3 as sole carbon and energy source was acquired. The yeast colony was mucoid creamy whitish with a diameter of approximate $4 \mu \mathrm{m}$ on PDA medium (Fig. 1). Yeast cells showed circular with an entire 


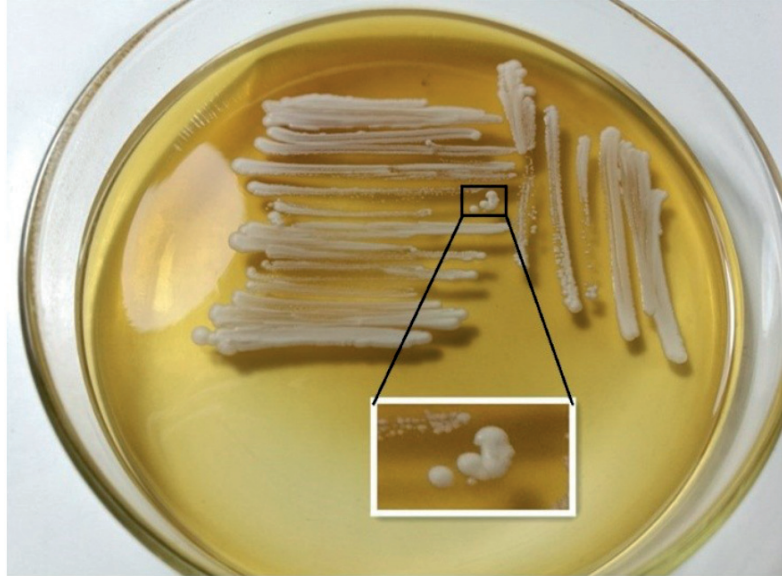

Fig. 1. The colony morphology of isolated 4-BDE degrading yeast strain.

margin. The molecular identification of the yeast strain was conducted by amplifying and sequencing the ITS fragment. Through aligning with sequences deposited in GenBank database, the obtained yeast showed highest similarity to Wickerhamomyces anomalus strain. Based on the morphological properties and the ITS sequence analysis, the isolated BDE-3 degrading yeast strain was identified as $W$. anomalus, and designated Y1. The phylogenic tree was illustrated in Fig. 2. The accession number of Y1 ITS sequence is MG757836.

\section{Growth Curve Establishment}

Activated yeast Y1 suspension supplied with BDE-3 (concentration gradient of $0,100,200,300$, $400,500 \mathrm{mg} \mathrm{L}^{-1}$ ) was set to determine the endurance capability with initial optical density at $660 \mathrm{~nm}\left(\mathrm{OD}_{660}\right)$ of 0.100 . As shown in the Fig. 3, the suspension $\mathrm{OD}_{660}$ of blank control group declined over time which illustrated no significant nutrition was residual after activating and washing procedure. The suspension $\mathrm{OD}_{660}$ increased along with the BDE-3 concentration from 100 to $500 \mathrm{mg} \mathrm{L}^{-1}$, revealing high BDE-3 concentration up to $500 \mathrm{mg} \mathrm{L}^{-1}$ did not limit the quantitative growth of strain Y1. The highest optical density at $660 \mathrm{~nm}$ of most treatment groups (4/5) reached at the second day, then slowly inclined. The highest $\mathrm{OD}_{660}$ of $500 \mathrm{mg} / \mathrm{L}$ BDE-3 treatment group came up to 0.450 at the 2 nd day. The nutrition level effect of liquid PDA medium and BDE-3 in BHMS on yeast biomass was conducted and it could be seen a huge suspension density difference between the two media (Fig. 3), where Y1 in liquid PDA reached the summit of suspension $\mathrm{OD}_{660}$ at $3^{\text {rd }}$ day and almost came up to 2.000 .

\section{Environmental Factors Tolerance Range Determination}

As shown in Fig. 4 (a-b), BDE-3 degrading yeast Y1 could grow on $300 \mathrm{mg} \mathrm{L}^{-1}$ BDE-3 in BHMS medium in $\mathrm{pH}$ range of 4.0 to 8.0 and up to $3 \% \mathrm{NaCl}$, respectively. If zoom in, the results showed that the yeast $\mathrm{Y} 1$ cells grew better at $\mathrm{pH} 6.0$ than 7.0, illustrating the yeast was mildly acidophilic. And yeast Y1 grew best in BHMS medium when no extra $\mathrm{NaCl}$ was added but could still survive at $3 \% \mathrm{NaCl}$, proving the yeast possessed strong salt tolerance capability.

\section{Removal Efficiency Determination}

The removal efficiency of BDE-3 degrading yeast Y1 was conducted by aerobically removing $40 \mathrm{mg} \mathrm{L}^{-1}$ BDE-3 with initial suspension $\mathrm{OD}_{660}$ of 0.100 . The results showed that no significant BDE-3 loss appeared in negative control group, thus ruling out the

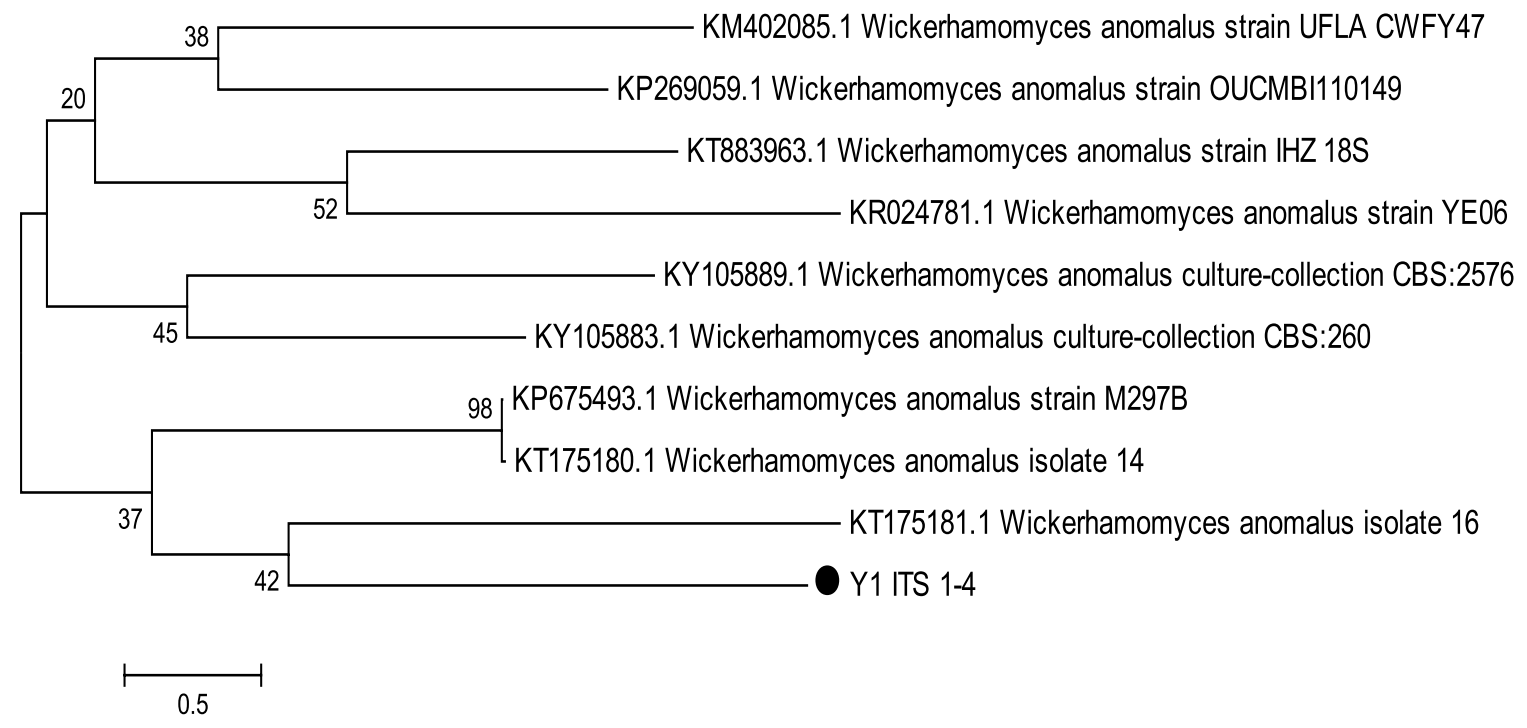

Fig. 2. The phylogentic tree of yeast Y1 based on ITS sequence. The black point represents the isolated phyllospheric yeast Y1, the 9 alignment strains are shown by accession number and name of species. 


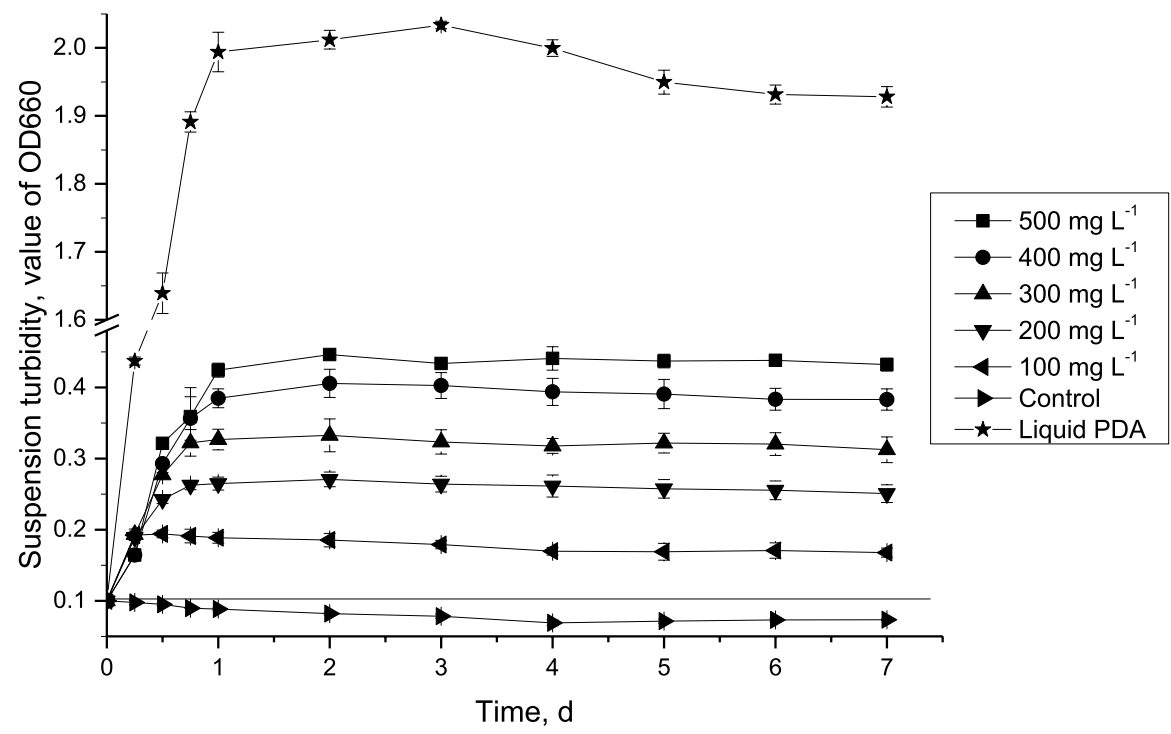

Fig. 3. Y1 growth curves in 4-BDE BHMS and liquid PDA media. The baseline of 0.1 means the initial suspension turbidity. The character $\mathrm{d}$ means day. The baseline of 0.1 means the initial suspension turbidity.
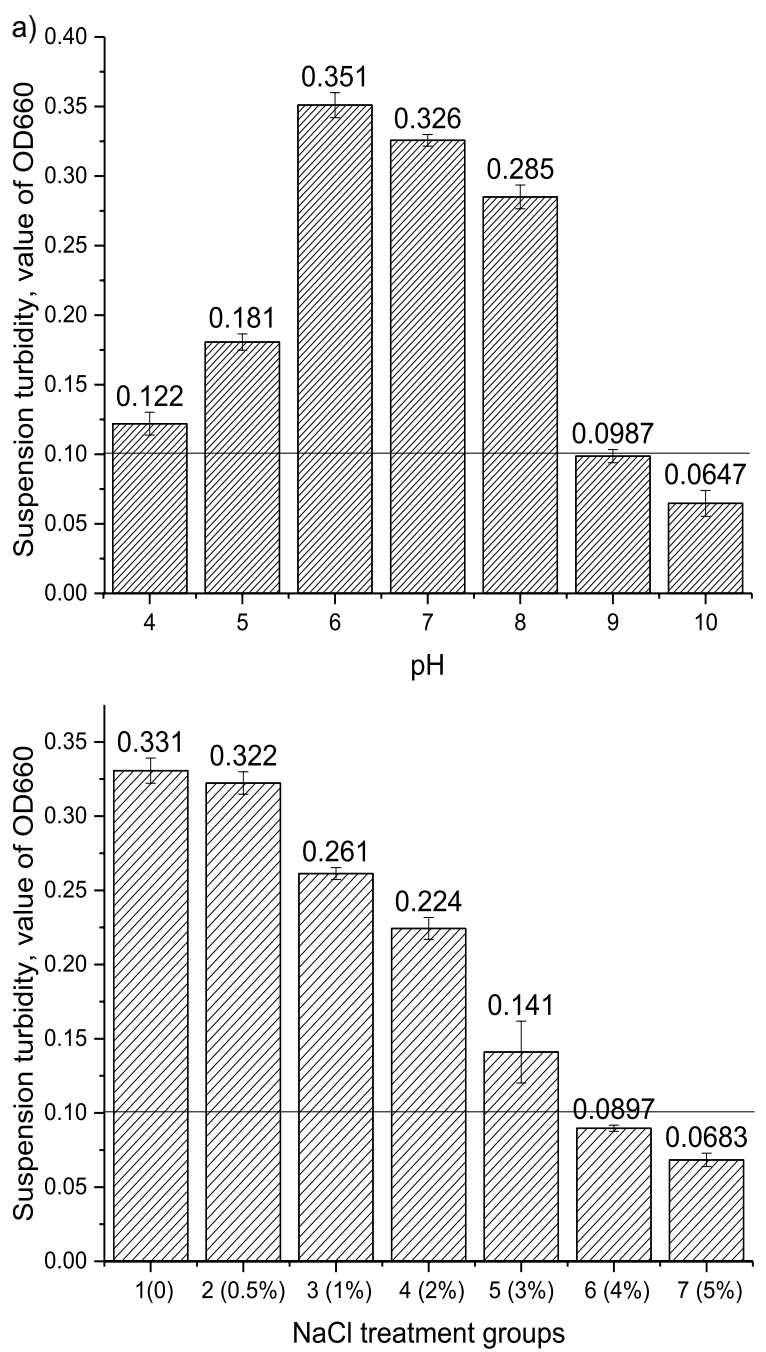

(The numbers in brackets represent the mass concentration)

Fig. 4. Yeast $\mathrm{Y} 1$ suspension turbidity in the range of $\mathrm{pH}$ a) and $\mathrm{NaCl}$ concentration b) after $5 \mathrm{~d}$ incubation. The baseline of 0.10 means the initial suspension turbidity possibility of significant volatilization or non-biological degradation of BDE-3. For biological removal treatment group, Y1 could transform $83.58 \pm 2.60 \%$ of $40 \mathrm{mg} \mathrm{L}^{-1}$ BDE-3 in 3-day incubation. For thermally inactivated Y1 suspension, inactive Y1 cells still could absorb and assimilate $41.13 \pm 4.95 \%$ of $40 \mathrm{mg} \mathrm{L}^{-1} \mathrm{BDE}-3$ (Table. 1).

The BDE-3 degrading yeast Y1 was originally isolated from the phyllosphere of P. tomentosa forest, where the survival environment is not significantly or continuously contaminated by PBDEs or other organic pollutants. For acquiring microbial resource for potential application to degrading hazardous materials, the contaminated areas of corresponding pollutant were the preferred investigation sites, where these sites could domesticate microorganisms with outstanding adaptive mechanisms and degrading properties. Most researches involved acquiring desired PBDEs-degrading strains were focused on sites of PBDEs contaminated field $[8,23,24]$. The finding of yeast $\mathrm{Y} 1$, with the specific ecological niche on phyllosphere, broadens the existing range of PBDEs degrading microorganisms, and as unicellular fungi, strain Y1 is the first report with property of biodegrading PBDEs. Phyllosphere, the aerial above-ground plant part, is a high-density microbial attachment area where more versatile noxious-substance degrading microorganisms to be further explored [25-26].

The addition of carbon and energy source to culture environment was needed necessarily for partial PBDEs degrading strains to maintain efficient removal rate [7, 27]. Moreover, the addition of extra energy materials could be beneficial to promoting cell surface hydrophobicity, thus enhancing the removal efficiency $[23,24,28]$. In the present research, the obtained yeast Y1 could grow on BDE-3 as sole carbon and energy source, which is great favor for engineering application: the utilization of yeast $\mathrm{Y} 1$ could reduce the economical 
Table 1. The BDE-3 removal efficiency of different treatment groups.

\begin{tabular}{|c|c|}
\hline Treatments & Removal efficiency (\%) \\
\hline BDE-3 removal group $^{\text {a }}$ & $83.58 \pm 2.60$ \\
\hline BDE-3 absorb group $^{\mathrm{b}}$ & $41.13 \pm 4.95$ \\
\hline Blank control group $^{\mathrm{c}}$ & $0.30 \pm 0.14$ \\
\hline
\end{tabular}

a: Y1 suspension with supplied of $40 \mathrm{mg} \mathrm{L}^{-1} \mathrm{BDE}-3$.

$\mathrm{b}$ : Thermally inactivated $\mathrm{Y} 1$ suspension with supplied of $40 \mathrm{mg} \mathrm{L}^{-1}$ BDE-3. c: BHMS medium without Y1 cells but $40 \mathrm{mg} \mathrm{L}^{-1} \mathrm{BDE}-3$. The removal efficiency is presented by means \pm SD of triplicates

and environmental burden caused by adding artificial co-metabolites or surfactants, and thus eliminate the possible adverse consequence if the additive materials are poisonous like toluene or other compounds possessing benzene ring structure.

In this paper, the aerobic transformation efficiency of yeast Y1 reached $83.58 \pm 2.60 \%$ of $40 \mathrm{mg} \mathrm{L}^{-1} \mathrm{BDE}-3$ in 3 days incubation, which is fairly or even more effective when comparing with the previous reports. For instance, Rhodococcus sp. RR1 aerobically transformed $20 \%$ of $17 \mathrm{ug} \mathrm{L}^{-1}$ BDE-3 within 72 hours [29]. Pseudomonas putida degraded $42.5 \%$ of $2 \mathrm{mg} \mathrm{L}^{-1}$ BDE-3 after 10 days incubation [10]. Two kinds of anaerobic sludge removed $77 \%$ and $31 \%$ of $5 \mathrm{mg} \mathrm{L}^{-1}$ BDE-3 respectively over 16 days [30]. Sphingomonas sp. PH-07 could degrade $23 \%$ of $1 \mathrm{~g} \mathrm{~L}^{-1}$ BDE-3 within 8 days [5].

\section{Conclusions}

The yeast strain with the ability to degrade 4-brominated diphenyl ether (BDE-3) was isolated from the phyllosphere of $P$. tomentosa at a subastral ecological niche without any contamination of synthetic chemicals. The strain was identified as Wickerhamomyces anomalus and designated Y1 whose $\mathrm{pH}$ tolerance rang was 4.0 to 8.0 , and could grow in the BHSM medium adding $3 \% \mathrm{NaCl}$. The yeast $\mathrm{Y} 1$ could remove $83.58 \pm 2.60 \%$ of $40 \mathrm{mg} \mathrm{L}^{-1} \mathrm{BDE}-3$ under an aerobic incubation condition within 3 days. The findings are expected to inspire the integral phytoremediation combining plant and associated above-ground microorganisms for gaseous PBDEs removal.

\section{Acknowledgements}

This work was supported by the Natural Science Foundation of Hebei Province (C2018204134), the National High Technology Research and Development Program of China (2012AA101403), and the National Natural Science Foundation of China (30972384).

\section{Contributions}

Kejiu Du contributed to the experimental design; Xinwei Zhao, Yaxiao Wang, Yuling Li, contributed significantly to analysis and manuscript preparation; Xinwei Zhao, Kejiu Du performed the data analyses and wrote the manuscript.

\section{Conflict of Interest}

The authors declare no conflict of interest.

\section{References}

1. SONG W., FORD J.C., LI A., STURCHIO N.C., ROCKNE K.J., BUCKLEY D.R., MILLS W.J. Polybrominated diphenyl ethers in the sediments of the Great Lakes. 3. Lakes Ontario and Erie. Environ. Sci. Technol, 39, 5600, 2005.

2. ANDERSSON Ö., BLOMKVIST G. Polybrominated aromatic pollutants found in fish from Sweden. Chemosphere, 10, 1051, 1981.

3. LAW R.J., COVACI A., HARRAD S., HERZKE D., ABDALLAH M.A., FERNIE K., TOMS L.M., TAKIGAMI H. Levels and trends of PBDEs and HBCDs in the global environment: status at the end of 2012 . Environ Int, 65 (2), 147, 2014.

4. RICHARDSON V., STASKAL D., ROSS D., DILIBERTO J., DEVITO M., BIRNBAUM L. Possible mechanisms of thyroid hormone disruption in mice by BDE 47, a major polybrominated diphenyl ether congener. Toxicol. Appl. Pharm, 226, 244, 2008.

5. KIM Y.M., NAM I.H., MURUGESAN K., SCHMIDT S., CROWLEY D.E., CHANG Y.S. Biodegradation of diphenyl ether and transformation of selected brominated congeners by Sphingomonas, sp. PH-07. Appl Microbiol Biotechnol, 77 (1), 187, 2007.

6. DENG D., GUO J., SUN G., CHEN X.J., QIU M.D., XU M.Y. Aerobic debromination of deca-BDE: Isolation and characterization of an indigenous isolate from a PBDE contaminated sediment. Int Biodeterior Biodegradation, 65 (3), 465, 2011.

7. SHI G., YIN H., YE J., PENG H., LI J., LUO C. Aerobic biotransformation of decabromodiphenyl ether (PBDE209) by Pseudomonas aeruginosa. Chemosphere, 93 (8), 1487, 2013.

8. ZHANG S.W., XIA X.H., XIA N., WU S., GAO F., ZHOU W.W. Identification and biodegradation efficiency of a newly isolated 2,2',4,4'-tetrabromodiphenyl ether (BDE-47) aerobic degrading bacterial strain. Int Biodeterior Biodegradation, 76, 24, 2013.

9. LI Y., CHEN L., NGOC D.M., DUAN Y.P., LU Z.B., WEN Z.H., MENG X.Z. Polybrominated diphenyl ethers (PBDEs) in PM2.5, PM10, TSP and gas phase in office environment in Shanghai, China: occurrence and human exposure. Plos One, 20, 10(3), e0119144, 2015.

10. LV Y.C.., LI LH., CHEN Y.C., TANG Z.H., HU Y.Y. Effects of glucose and biphenyl on aerobic cometabolism of polybrominated diphenyl ethers by Pseudomonas putida: Kinetics and degradation mechanism. Int Biodeterior Biodegradation, 108, 76, 2016. 
11. DENG D., TAM F.Y. Isolation of microalgae tolerant to polybrominated diphenyl ethers (PBDEs) from wastewater treatment plants and their removal ability. Bioresour Technol, 177, 289, 2015.

12. WANG S., ZHANG S., HUANG H., LU A., PING H. Debrominated, hydroxylated and methoxylated metabolism in maize (Zea mays L.) exposed to lesser polybrominated diphenyl ethers (PBDEs). Chemosphere, 89 (11), 1295, 2012.

13. SUN J., LIU J., YU M., WANG C., SUN Y., ZHANG A., WANG T., LEI Z., JIANG G. In vivo metabolism of 2,2',4,4'-tetrabromodiphenyl ether (BDE-47) in young whole pumpkin plant. Environ Sci Technol, 47 (8), 3701, 2013.

14. YU M., LIU J., WANG T., SUN J., LIU R., JIANG G. Metabolites of 2,4,4'-tribrominated diphenyl ether (BDE-28) in pumpkin after in vivo and in vitro exposure. Environ Sci Technol, 47 (23), 13494, 2013.

15. TAN L., LI H., NING S., XU B. Aerobic decolorization and degradation of azo dyes by suspended growing cells and immobilized cells of a newly isolated yeast Magnusiomyces ingens LH-F1. Bioresour Technol, 158 (4), 321, 2014.

16. PAN F., YANG Q., ZHANG Y., ZHANG S., YANG M. Biodegradation of polycyclic aromatic hydrocarbons by Pichia anomala. Biotechnol Lett, 26 (10), 803, 2004.

17. MEEHAN C., BANAT I.M., MUMULLAN G., NIGAM P., SMYTH F., MARCHANT R. Decolorization of Remazol Black-B using a thermotolerant yeast, Kluyveromyces marxianus IMB3. Environ Int, 26 (1-2), 75, 2000.

18. WU Y., HU Y., XIE Z., FENG S., LI B., MI X. Characterization of biosorption process of acid orange 7 on waste brewery's yeast. Appl Biochem Biotech, 163, 882, 2011.

19. AHUATZI-CHACON D., ORDORICA-MORALES G., RUIZ-ORDAZ N., CRISTIANI-URBINA E., JUAREZRAMIREZ C., GALINDEZ-MAYER J. Kinetic study of phenol hydroxylase and catechol 1,2-dioxygenase biosynthesis by Candida tropicalis cells grown on different phenolic substrates. World J Microb Biot, 20, 695, 2004.

20. BERGAUER P., FONTEYNE P.A., NOLARD N., SCHINNER F., MARGESIN R. Biodegradation of phenol and phenol-related compounds by psychrophilic and cold-tolerant alpine yeasts. Chemosphere, 59, 909, 2005.
21. ZHAO X.W., LIU M., LIU Y.C., LI Y.L., ZHUANG S., DU K.J. Aerobic degradation of 4-monobrominated diphenyl ether: identifying and characterizing three strains isolated from Populus tomentosa phyllosphere. Pol. J. Environ. Stud, 26 (3), 1385, 2017.

22. WHITE T., BRUNS T., LEE S., TAYLOR J. In: PCR Protocols and Applications - A Laboratory Manual, San Diego, Academic Press, 315, 1990.

23. TANG S., YIN H., CHEN S., PENG H., CHANG J., LIU Z. Dang Aerobic degradation of BDE-209 by Enterococcus casseliflavus: Isolation, identification and cell changes during degradation process. J Hazard Mater, 308, 335, 2016.

24. STIBOROVA H., VRKOSLAVOVA J., LOVECKA P., PULKRABOVA J., HRADKOVA P., HAJSLOVA J., DEMNEROVA K. Aerobic biodegradation of selected polybrominated diphenyl ethers (PBDEs) in wastewater sewage sludge. Chemosphere, 118, 315, 2015.

25. LINDOW S.E., BRANDL M.T. Microbiology of the phyllosphere. Appl Environ Microbiol, 69 (4), 1875, 2003.

26. REDFORD A.J., BOWERS R.M., KNIGHT R., LINHART Y., FIERER N. The ecology of the phyllosphere: geographic and phylogenetic variability in the distribution of bacteria on tree leaves. Environ Microbiol, 12 (11), $2885,2010$.

27. CHEN J., ZHOU H.C., WANG C., ZHU C.Q., TAM N.F. Short-term enhancement effect of nitrogen addition on microbial degradation and plant uptake of polybrominated diphenyl ethers (PBDEs) in contaminated mangrove soil. J Hazard Mater, 300:84-92, 2015.

28. TANG S., BAI J., YIN H., YE J., PENG H., LIU Z., DANG Z. Tea saponin enhanced biodegradation of decabromodiphenyl ether by Brevibacillus brevis. Chemosphere, 114 (22), 255, 2014.

29. ROBROCK K.R., COELHAN M., SEDLAK D.L., ALVAEZ-COHEN L. Aerobic biotransformation of polybrominated diphenyl ethers (PBDEs) by bacterial isolates. Environ Sci Technol, 43, 5705, 2009.

30. SHIH Y.H., CHOU H.L., PENG Y.H. Microbial degradation of 4-brominated diphenyl ether with anaerobic sludge. J Hazard Mater, 30, 213-214:341-6, 2012. 